\title{
Fertility Parameters of Male and Female Rats Simultaneously Treated with Aqueous Extract of Eremomastax speciosa
}

\author{
B. Nchegang1, P.A. Amang'2, C. Mezui ${ }^{3}$, Z.E. Nkwengoua4, P.V. Tan ${ }^{5, *}$
}

${ }^{1}$ Department of Fisheries and Aquatic Ecosystems Management, Institute of Fisheries and Aquatic Sciences at Yabassi, University of Douala, P.O. Box 2701 Douala-Cameroon.

${ }^{2}$ Department of Biological Sciences, Faculty of Science, University of Maroua, P.O. Box 814, Yaoundé, Cameroon.

${ }^{3}$ Department of Biological Sciences, Higher Teachers' Training College, 'University of Yaoundé I, P.O Box 047. Yaoundé, Cameroon.

${ }^{4}$ Department of Organic Chemistry, Faculty of Science, University of Yaoundé I, P.O Box 84, Yaoundé, Cameroon.

${ }^{5}$ Department of Animal Biology and Physiology, Faculty of Science, University of Yaoundé I, P.O Box 812, Yaoundé, Cameroon.

\section{A R T I C L E D E T A I L S}

\section{Article history:}

Received 25 June 2020

Accepted 17 July 2020

Available online 24 July 2020

\section{Keywords:}

Eremomastax speciose

Reproduction

Fertility

Toxicity

Rat

\begin{abstract}
A B S T R A C T
Eremomastax speciosa is widely used in ethnomedicine for various purposes, but the possible toxic effects on fertility parameters following sub-acute intake have not been studied. 36 immature male and 36 adult female rats were each divided into four groups of nine rats (Control, Extract 250, 500, 1000 $\mathrm{mg} / \mathrm{kg}$ ). Males received extract for 60 days and females for 14 days. From day 15, a fertility study was done by cohabiting one male with one female from each corresponding group for 10 days. In males, plant extract (250-1000 mg/kg; p 0.01) reduced testicular and spleen weights, increased epididymis weights $(250-500 \mathrm{mg} / \mathrm{kg} ; \mathrm{p}<0.001)$ and increased spermatozoa density and motility (at $250 \mathrm{mg} / \mathrm{kg}$ ). In females, the extract did not influence number of uterine resorptions and number of live offspring compared with controls. Red blood cell count significantly increased $(\mathrm{p}<0.01)$ in males and significantly decreased $(\mathrm{p}<0.05)$ in females compared with controls. Simultaneous treatment of male and female rats with the extract of $E$. speciosa does not negatively affect reproductive performance. E. speciosa may be safely used by reproducing couples at the dose of $250 \mathrm{mg} / \mathrm{kg}$ for the management of various disease conditions without the risk of reproductive toxicity.
\end{abstract}

\section{Introduction}

The use of medicinal plants as sources of medicine has gone on for several hundred years in many cultures of the world. In recent decades the acceptance and use of plant products as alternative therapy in place of synthetic modern medicines has witnessed a dramatic rise [1]. Top among the various reasons advanced for this turn of events is the debatable assertion that "natural" products are harmless, and that conventional medicines can be ineffective due to side effects and inefficient therapy [2]. A historic review of the use of minerals, plant and animal products as sources of drugs is provided by De Pasquale [3]. Although the WHO considers phytotherapy in its health programs, strict guidelines and basic procedures for the validation of drugs from plant origin in developing countries have been issued, and eastern countries, such as China and India, have developed well-established herbal medicines industry. In the same vein, Latin American countries have been investing huge resources in research programs on medicinal plants and the standardization and regulation of phytomedicines, following the example of European countries, such as France and Germany. In North America, the provision of information on efficacy and safety of phytomedicines products sold as "health foods" isa mandatory requirement for their registration by the FDA [2]. These measures and cautious approaches underline the importance of standards and safety considerations for the use of plant-derived products in health care systems. Thus, in addition to the systemic toxicity (acute, sub-acute, sub chronic), and local toxicity tests, the WHO recommends that special toxicity tests for mutagenicity, and additional toxicity tests such as carcinogenicity, teratogenicity and reproduction studies be carried out especially when deviations from traditional use (new uses, new routes or more prolonged administration) are contemplated [4].

Eremomastax speciosa (Hochst.) Cufod. (Acanthaceae) is widespread from West Africa through Central African Republic and N. Congo-Kinshasa to S. Sudan and S.W. Ethiopia, Madagascar. The plant is widely distributed in tropical Africa and is the only species of the genus Eremomastax (syn: Paulownia helmia (Lindau); and Ruellia (S. Moore)) [5]. The robust, polymorphous shrub is commonly referred to in Cameroon as 'blood plant' due to its reputed use in the treatment of cases of anemia. Its widelyclaimed anti-anemic activity has been experimentally demonstrated by workers Okoko et al. [6] who also showed anti-microbial actions against pure clinical cultures of Staphylococcus aureus, E. coli, Candida albicans and Aspergillus niger. It is also used in Cameroonian ethnomedicine for the treatment of various stomach complaints and information from tradipractitioners suggested that it possesses antiulcer effects. The leaf aqueous extract has antidiarhoeal activity [7]. The Douala peoples of Cameroon employ E. Speciosa variously for malaria, kidney pain, scabies, anemia, diabetes, and nerves pain [8]. The plant has been cited [9] for the treatment of menstrual pains, gonorrhea, appendicitis and dry burns; as an anti-poison, and to increase and purify blood in the mount Cameroon region. Comparative phytochemical screening of $E$. speciosa revealed the presence of flavonoids, alkaloids, phenols, tannins, terpenes and saponins [10]. E. speciosa has also been cited for its local use in the treatment of female infertility in the west region of Cameroon [11], for the treatment of male infertility among the Ifa Nkari People of Akwa Ibom State, Nigeria [12], as well as for the treatment of irregular menstruation by the Aguambu-Bamumbu poeples of the Lebialem highlands in the South West Region of Cameroon [13]. The medicinal importance has also been documented in the Cameroonian and Ghanaian Government/WHOsponsored ethnobotanical surveys $[14,15]$. The antiulcer activity of the extracts includes cytoprotection [16], anticholinergic and antihistaminergic actions, as well as healing effects against chronic gastric ulcers [17]. Since the extract of E. speciosa is widely used to treat many conditions, it is important that possible secondary effects related to reproductive physiology are taken into consideration during prescription. In the present experiment we studied the effects of the aqueous extract of E. speciosa on the reproductive performance and fertility parameters of male and female rats that were given the extract simultaneously. 


\section{Experimental Methods}

\subsection{Experimental Animals}

Male immature (35 - 40 days) and female adult (75 days) albino Wistar rats (70-75 g and 110-125 g, respectively) raised in the animal house of the Animal Physiology Laboratory, Faculty of Science, University of Yaoundé 1, were used. The animals were maintained in a well-ventilated room with a 12:12 hour light/dark cycle at room temperature. They were fed a standard laboratory diet (supplied by SPC Ltd, Bafoussam, Cameroon) and given tap water ad libitum. Prior authorization for the use of laboratory animals in this study was obtained from the Cameroon National Ethics Committee (Reg. No. FWA-IRB00001954). The use, handling and care of animals were done in adherence to the European Convention (Strasbourg, 18.III.1986) for the protection of vertebrate animals used for experimental and other purposes (ETS-123), with particular attention to Part III, articles 7; 8 and 9.

\subsection{Plant Material and Preparation of the Aqueous Extract}

The plant material (Eremomastax speciosa) (Fig. 1) was collected from the outskirts of Yaoundé between August and September 2014 and identified at the National Herbarium, Yaoundé, where voucher specimen No. HNC/136984 has been deposited. The aqueous extract of E. speciosa was prepared by infusing $560 \mathrm{~g}$ of the ground powder in 5 liters of boiled water for 15 minutes. After filtration through Whatman filter paper No. 3, the filtrate was evaporated at $40{ }^{\circ} \mathrm{C}$ using a Raven convection air oven (Jencons-PLS, UK). The brownish solid obtained ( $10 \%$ yield) was stored at $4{ }^{\circ} \mathrm{C}$. The crude extract dissolved readily in distilled water which was used as vehicle in the subsequent experiments.

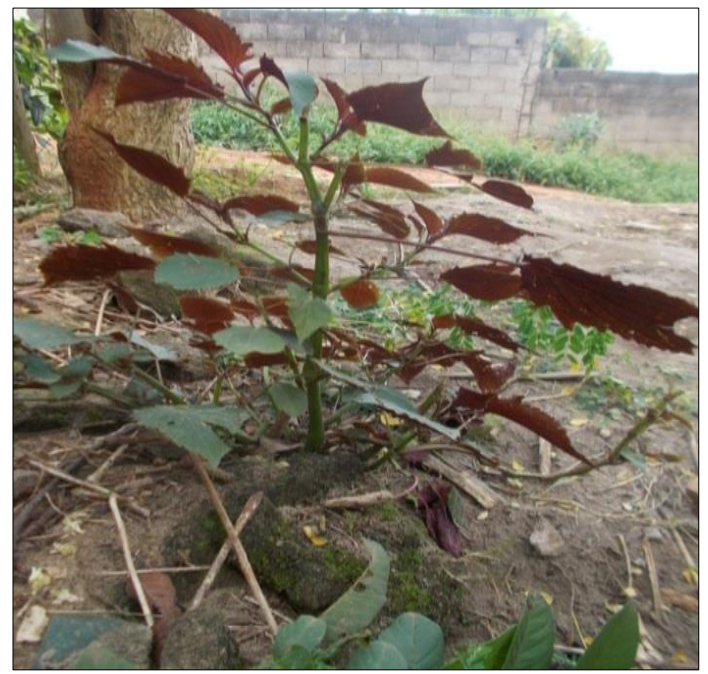

Fig. 1 Photograph of Eremomastax speciosa

\subsection{Experimental Protocol}

The protocol employed was the segment 1 study procedure (administration of test substance prior to and in the early stages of pregnancy) recommended for reproductive and development toxicity [4]. Thirty-six immature male rats were randomly divided into four groups of nine rats each. Group I served as the control and received distilled water ( $2.5 \mathrm{~mL} / \mathrm{kg}$ of body weight) while groups II, III and IV rats were treated orally with 250,500 and $1000 \mathrm{mg} / \mathrm{kg}$ of body weight of the aqueous extract of E. speciosa, respectively, for 60 days (the duration of treatment depends on the duration of spermatogenesis which is 54 days in rats). Thirty-six adult female rats were also randomly divided into four similar groups of nine rats each and given the extract $(0 ; 250,500,1000 \mathrm{mg} / \mathrm{kg}$ of body weight) orally for 14 days (beginning 47 days from the start of male rats' treatment). At the end of the treatment period ( 60 days for the males and 14 days for the females) a fertility study was done by cohabiting one male with one female from each corresponding group for 10 days. The females were examined regularly and the presence of a vaginal plug was taken as a positive indicator for mating and considered the first day of pregnancy. Extract administration for the males continued until successful copulation and administration for the females continued during mating and after successful copulation until the beginning of organogenesis. During the experimental period, mortality was recorded, general signs were noted and body weights and food intake were measured. After successful copulation, the males were sacrificed and autopsied. The testis, epididymis, prostate, penis, heart, liver spleen, lung and kidneys were removed and weighed, relative organ weights (ROW) were calculated as: https://doi.org/10.30799/jnpr.087.20060103
ROW $=$ [absolute organ weight $(\mathrm{g}) /$ body weight on the day of sacrifice $(\mathrm{g})]$ $\mathrm{x} 100$, and samples were preserved in $10 \%$ neutral buffered formaldehyde solution for subsequent histological analysis.

\subsubsection{Fertility Parameters}

The females were autopsied on the $12^{\text {th }}$ day of gestation and examined for the number of ovarian corpora lutea, number of successful pregnancies and number of uterine resorptions. Non-gravid uteri were subjected to ammonium sulphide staining for confirmation of non-pregnant status and number of corpora lutea and resorptions were noted. In addition, gross examinations of the organs and tissues were carried out. The left cauda epididymis of each male rat was split into $3 \mathrm{~mm}$ pieces in a petri dish containing $10 \mathrm{~mL}$ of $\mathrm{NaCl}(0.9 \%)$. The solution was incubated at $37{ }^{\circ} \mathrm{C}$ for $10 \mathrm{~min}$., and an aliquot observed under a light microscope (10x mag.) for sperm motility. Sperm counts (millions/mL of suspension) were made using a haemocytometer. A separate aliquot of sperm was stained in $1 \%$ eosin and a glass slide smear examined for spermatozoa morphological deformities.

\subsubsection{Haematology and Organ Biochemistry}

The animals were weighed and sacrificed using an overdose of ether. Each rat was opened up surgically and blood samples were drawn by cardiac puncture. Blood was collected into tubes with and without ethylene diamine tetra acetic acid (EDTA) for hematological and biochemical analysis, respectively. The internal organs such as testis, ovaries and uterus were homogenized in 1- $4 \mathrm{~mL}$ of Tris buffer solution, centrifuged at $2000 \mathrm{rpm}$ for $20 \mathrm{~min}$. and the homogenates stored at $-20^{\circ} \mathrm{C}$ for biochemical analysis.

\subsubsection{Hematological Parameters}

Hematological analyses were performed on total blood collected in tubes with EDTA. Red blood cell count (RBC), white blood cell count (WBC), differential leukocyte count (lymphocyte, monocyte, granulocyte), platelets (PLT), hemoglobin (HGB), hematocrit (HCT), mean corpuscular hemoglobin concentration (MCHC), mean corpuscular hemoglobin (MCH) and mean corpuscular volume (MCV), distribution index of red blood cells (RDW), standard deviation of red blood cell distribution index (RDW-SD), mean platelet volume (MPV), procalcitonin (PCT), and platelet distribution index (PDW) were determined using an automatic analyzer (Hospitex Diagnostics Hema Screen 18).

\subsubsection{Dosage of Serum Cholesterol, Proteins and Transaminases}

Biochemical analyses were performed on serum obtained after centrifugation of total blood without anticoagulant at $2000 \mathrm{rpm}$ for 15 min. The analysis of transaminase activities (ASAT, ALAT), total protein and total cholesterol, were estimated in serum using Commercial kits (Fortress and GCM). Enzymatic activities and atherogenic index were calculated as described by various authors [18-20].

\subsubsection{Dosage of Tissue Proteins and Cholesterol}

Biochemical analyses were performed on homogenates obtained after homogenization and centrifugation of tissue samples (testis, ovaries or uterus) at $2000 \mathrm{rpm}$ for $20 \mathrm{~min}$. and stored at $-20^{\circ} \mathrm{C}$. The analysis of total protein and total cholesterol in homogenates were done using commercial kits (Fortress and GCM). Atherogenic index was calculated as described by authors Gornal et al. and Youmbissi et al. [19, 20].

\subsubsection{Histological Processing}

The procedure described by Akpantah et al. [21] was essentially followed. The organs (testes and ovaries initially preserved in 10\% neutral buffered formaldehyde solution) were transversely cut in slabs of $0.5 \mathrm{~cm}$ thick and fixed in Bouin solution for a day after which it was transferred to $70 \%$ alcohol for dehydration. The tissues were passed through $90 \%$ alcohol and chloroform for different durations before they were transferred into two changes of molten paraffin wax for 20 minutes each in an oven at $57{ }^{\circ} \mathrm{C}$. Serial sections were cut using a rotary microtome at 5 microns. Slides were prepared from these tissues. The slides where dew axed and passed through absolute alcohol (two changes); $70 \%$ alcohol and then to water for 5 minutes. The slides where then stained with haematoxylin.

\subsubsection{Statistical Analysis}

The results were analyzed using the one-way ANOVA followed by the Student-Newman-Keuls posttest for comparison of treatment means. $P$ values $<0.05$ were considered significant. Values in tables are given as means \pm standard error for the mean (SEM). 


\section{Results and Discussion}

\subsection{Effect of Extract on Body Weight Gain and Relative Organ Weights}

The results showed that the rats that received the aqueous extract of $E$. speciosa $(250-1000 \mathrm{mg} / \mathrm{kg})$ had significantly higher body weights at the end of the experimental period compared with the controls, even though food intake reduced progressively with time for all the treatments (Figs. 2 and 3).

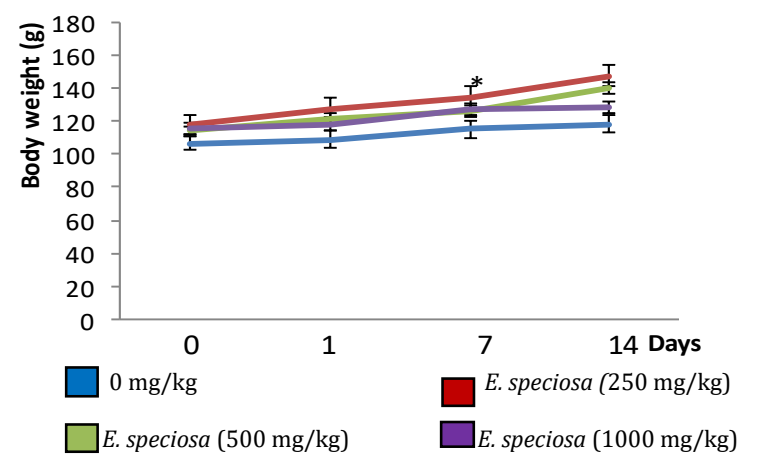

Fig. 2 Effects of the aqueous extract of E. speciosa on body weight in female rats (Statistically significant relative to the controls, ${ }^{*} \mathrm{p}<0.05 ;{ }^{* *} \mathrm{p}<0.01{ }^{* * *} \mathrm{p}<0.001$ )

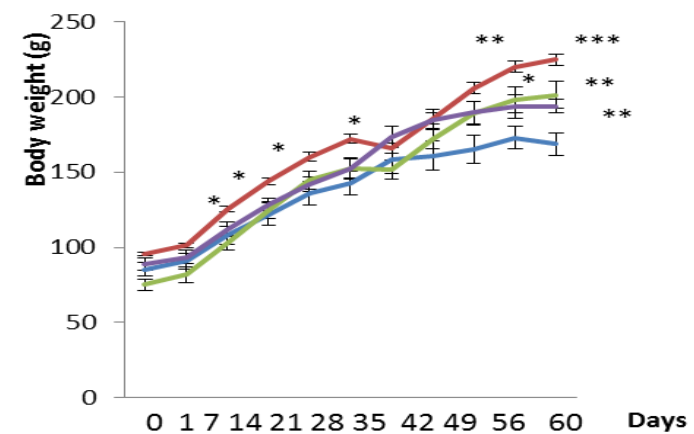

Fig. 3 Effects of the aqueous extract of E. speciosa on body weight in male rats (Statistically significant relative to the controls, ${ }^{*} \mathrm{p}<0.05{ }^{* *} \mathrm{p}<0.01 ;{ }^{* * *} \mathrm{p}<0.001$ )

Table 1 Relative organ weights (g/100 g of bw) of female rats treated (14 days) with aqueous extract of E. speciosa

\begin{tabular}{lllll}
\hline Organs & \multicolumn{4}{l}{ Treatment group $(\mathrm{mg} / \mathrm{kg})$} \\
\cline { 2 - 5 } & 0 & 250 & 500 & 1000 \\
\hline Lungs & $1.04 \pm 0.12$ & $1.02 \pm 0.06$ & $0.85 \pm 0.08$ & $0.87 \pm 0.004$ \\
Liver & $5.29 \pm 0.57$ & $4.44 \pm 0.33$ & $3.17 \pm 0.33^{* *}$ & $4.43 \pm 0.28$ \\
Heart & $0.35 \pm 0.01$ & $0.34 \pm 0.01$ & $0.32 \pm 0.02$ & $0.30 \pm 0.01$ \\
Spleen & $0.31 \pm 0.02$ & $0.44 \pm 0.02^{*}$ & $0.34 \pm 0.02$ & $0.37 \pm 0.03$ \\
Left kidney & $0.32 \pm 0.008$ & $0.38 \pm 0.02$ & $0.32 \pm 0.02$ & $0.29 \pm 0.009$ \\
Right Kidney & $0.31 \pm 0.01$ & $0.35 \pm 0.01$ & $0.31 \pm 0.01$ & $0.28 \pm 0.01$ \\
Left ovary & $0.04 \pm 0.005$ & $0.04 \pm 0.006$ & $0.03 \pm 0.004$ & $0.01 \pm 0.002^{* *}$ \\
Right ovary & $0.04 \pm 0.005$ & $0.03 \pm 0.007$ & $0.02 \pm 0.003^{*}$ & $0.02 \pm 0.004^{*}$ \\
Uterus & $0.51 \pm 0.11$ & $1.04 \pm 0.26$ & $0.43 \pm 0.09$ & $0.70 \pm 0.11$ \\
Placenta & $0.13 \pm 0.02$ & $0.17 \pm 0.02$ & $0.08 \pm 0.008$ & $0.13 \pm 0.02$ \\
\hline Values are expressed
\end{tabular}

Values are expressed as Mean \pm SEM of 9 rats per group. Statistically significant relative to the controls, ${ }^{*} p<0.05 ;{ }^{* *} p<0.01$

Table 2 Relative organ weights (g/100 g of bw) of male rats treated (60 days) with aqueous extract of $E$. speciosa

\begin{tabular}{lllll}
\hline Organs & \multicolumn{4}{l}{ Treatment group $(\mathrm{mg} / \mathrm{kg})$} \\
\cline { 2 - 5 } & 0 & 250 & 500 & 1000 \\
\hline Penis & $0.11 \pm 0.007$ & $0.14 \pm 0.001$ & $0.11 \pm 0.008$ & $0.10 \pm 0.004$ \\
Lungs & $0.86 \pm 0.05$ & $0.69 \pm 0.08$ & $0.69 \pm 0.05$ & $0.70 \pm 0.05$ \\
Liver & $2.50 \pm 0.07$ & $2.59 \pm 0.15$ & $2.55 \pm 0.07$ & $2.78 \pm 0.21$ \\
Heart & $0.31 \pm 0.007$ & $0.28 \pm 0.01$ & $0.30 \pm 0.01$ & $0.31 \pm 0.01$ \\
Spleen & $0.29 \pm 0,01$ & $0.19 \pm 0.01^{* * *}$ & $0.21 \pm 0.01^{* *}$ & $0.26 \pm 0.02$ \\
Left kidney & $0.32 \pm 0.01$ & $0.28 \pm 0.01$ & $0.28 \pm 0.009$ & $0.31 \pm 0.02$ \\
Right kidney & $0.32 \pm 0.01$ & $0.28 \pm 0.01$ & $0.28 \pm 0.01$ & $0.29 \pm 0.01$ \\
Left Testes & $0.72 \pm 0.02$ & $0.55 \pm 0.03^{* *}$ & $0.57 \pm 0.02^{* *}$ & $0.59 \pm 0.02^{* *}$ \\
Right Testes & $0.72 \pm 0.02$ & $0.59 \pm 0.01^{*}$ & $0.53 \pm 0.04^{* * *}$ & $0.57 \pm 0.01^{* *}$ \\
Left Epididymis & $0.19 \pm 0.008$ & $0.29 \pm 0.01^{* * *}$ & $0.31 \pm 0.02^{* * *}$ & $0.18 \pm 0.01$ \\
Right Epididymis & $0.20 \pm 0.007$ & $0.28 \pm 0.01^{* * *}$ & $0.30 \pm 0.01^{* * *}$ & $0.17 \pm 0.01$ \\
Prostate & $0.10 \pm 0.01$ & $0.13 \pm 0.01$ & $0.15 \pm 0.02$ & $0.15 \pm 0.01$ \\
Seminal vesicle & $0.42 \pm 0.04$ & $0.52 \pm 0.03$ & $0.38 \pm 0.03$ & $0.37 \pm 0.01$ \\
\hline Values are
\end{tabular}

Values are expressed as Mean \pm SEM of 9 rats per group. Statistically significant relative to the controls, ${ }^{*} p<0.05 ;{ }^{* *} p<0.01 ;{ }^{* * *} p<0.001$

https://doi.org/10.30799/jnpr.087.20060103
Tables 1 and 2 show the effects of the extract on vital and reproductive organ weights of females and males respectively. In the male rats treated with the extract for 60 days, there was a significant dose-dependent increase in the relative weights of spleens and epididymis, and a significant dose-dependent reduction of testicular weights. In the female rats treated for 20 days (14 days and up to the beginning of organogenesis), there was a significant dose-dependent drop in relative weights of ovaries, with up to $50-60 \%$ decrease at the highest dose of extract compared with the controls. Relative weights of spleen increased while liver weights decreased significantly $(\mathrm{p}<0.01)$ up to the $500 \mathrm{mg} / \mathrm{kg}$ dose.

\subsection{Effect of Extract on Fertility Parameters}

Administration of the extract of E. Speciosa to the male rats for 60 days resulted in significant increases in spermatozoa motility $(\mathrm{p}<0.01)$ and density of spermatozoa $(\mathrm{p}<0.05)$ at the dose of $250 \mathrm{mg} / \mathrm{kg}$ compared with controls. Significant differences did not appear at the higher doses of extract (Table 3).

Table 3 Sperm characteristics of rats treated (60 days) with the aqueous extract of E. speciosa

\begin{tabular}{lll}
\hline Treatment $(\mathrm{mg} / \mathrm{kg}$ of bw) & Motility (\%) & Sperm counts (million/mL) \\
\hline 0 & $72.47 \pm 4.41$ & $130.55 \pm 18.47$ \\
250 & $88.18 \pm 3.47^{* *}$ & $169.44 \pm 10.93^{*}$ \\
500 & $80.63 \pm 4.26$ & $117.50 \pm 27.78$ \\
1000 & $75.71 \pm 6.68$ & $126.66 \pm 11.86$ \\
\hline
\end{tabular}

Values are expressed as Mean \pm SEM of 9 rats per group. Statistically significant relative to the controls, ${ }^{*} p<0.05 ;{ }^{* *} p<0.01$

Table 4 shows the effects of the extract on fertility parameters in the female rats. Percentage coupling increased from 55.55\% in the controls to $88.88 \%$ at the highest dose of extract. Of the successful copulations, the number of gravid females was $5 / 5,7 / 8,7 / 7$ and $6 / 9$, respectively, for the controls, 250, 500 and $1000 \mathrm{mg} / \mathrm{kg}$ dose. Consequently, percentage fertility increased from $55.55 \%$ in the controls to $66.6-77.77 \%$ in the extract-treated females. On the $12^{\text {th }}$ day of gestation, the number of corpora lutea was $1.33 \pm 0.55$ in the control rats compared with $2.44 \pm 0.37$ - $3.33 \pm 0.64$ in the rats treated with E. speciosa extract, representing a percentage increase of $83-150 \%$. This was accompanied by an increase in the number of embryos from 4 in the controls to between 5 and 6 in the extract-treated females. The extract had no effect on the total number of implantation sites, but reduced the total number of resorptions per treatment group from 17 in the controls to 8 in the extract-treated groups.

Table 4 Effects of aqueous extract of E. speciosa on fertility parameters of female rats

\begin{tabular}{lllll}
\hline Fertility parameters & \multicolumn{5}{l}{ Dose $(\mathrm{mg} / \mathrm{kg}$ of bw) } \\
\cline { 2 - 5 } & 0 & \multicolumn{1}{l}{250} & \multicolumn{1}{l}{500} & \multicolumn{1}{c}{1000} \\
\hline Number of implantations & $6.00 \pm 2.06$ & $5.88 \pm .25$ & $6.55 \pm 1.40$ & $6.00 \pm 1.64$ \\
Number of fetuses (day 12) & $4.11 \pm 1.34$ & $5.00 \pm 1.01$ & $5.66 \pm 1.15$ & $5.11 \pm 1.29$ \\
Corpora lutea (day12) & $1.33 \pm 0.50$ & $2.44 \pm 0.37$ & $3.33 \pm 0.64$ & $2.44 \pm 0.68$ \\
Number of resorptions & $1.88 \pm 0.88$ & $0.88 \pm 0.45$ & $0.88 \pm 0.38$ & $0.88 \pm 0.77$ \\
Total resorptions per group & 17 & 08 & 08 & 08 \\
Number of live young & $4.11 \pm 1.34$ & $5.00 \pm 1.01$ & $5.66 \pm 1.15$ & $5.11 \pm 1.29$ \\
Copulation rate (\%) & 55.6 & 88.9 & 77.8 & 88.9 \\
Gravidity rate (\%) & 100 & 87.5 & 100 & 75.0 \\
Fertility rate (\%) & 55.6 & 77.8 & 77.8 & 66.7 \\
\hline Values are & & & &
\end{tabular}

Values are expressed as mean $\pm S E M,(n=9)$

\subsection{Effect of Extract on Haematological Parameters}

Tables 5 and 6 show the effects of the extract on haematological parameters. Extract treatment of males for 60 days resulted in significant increases in lymphocytes, red blood cells, haematocrit, haemoglobin, blood platelets and mean corpuscular haemoglobin concentration. Maximum effects of extract were obtained with the $500 \mathrm{mg} / \mathrm{kg}$ dose although effects at $1000 \mathrm{mg} / \mathrm{kg}$ were still higher than in controls (Table 5). The only significant effects of the extract on female rats treated for 20 days were the drop in red blood cell counts and haematocrit for all the doses compared with the controls. As in the male rats, the $500 \mathrm{mg} / \mathrm{kg}$ dose had more significant effect compared with the $1000 \mathrm{mg} / \mathrm{kg}$ dose (Table 6).

Table 5 Effects of aqueous extract of E. speciosa on haematological parameters in male rats

\begin{tabular}{lllll}
\hline Haematological & \multicolumn{4}{l}{ Treatment groups $(\mathrm{mg} / \mathrm{kg})$} \\
\cline { 2 - 5 } parameters & 0 & 250 & 500 & 1000 \\
\hline White Blood Cells $^{\mathrm{a}}$ & $5.18 \pm 0.75$ & $4.92 \pm 1.03$ & $6.81 \pm 1.12$ & $5.68 \pm 0.85$ \\
Lymphocyte $^{\mathrm{a}}$ & $1.65 \pm 0.26$ & $3.61 \pm 0.81$ & $4.94 \pm 0.75^{* *}$ & $2.19 \pm 0.34$ \\
Mid cells total count $^{\mathrm{a}}$ & $0.70 \pm 0.12$ & $0.84 \pm 0,15$ & $1.19 \pm 0.26$ & $0.98 \pm 0.16$ \\
\hline
\end{tabular}




\begin{tabular}{|c|c|c|c|c|}
\hline Granulocytes & $2.83 \pm 0.51$ & $0.47 \pm 0.08^{* * *}$ & $0.67 \pm 0.17^{* * *}$ & $2.51 \pm 0.47$ \\
\hline Red blood cells ${ }^{b}$ & $3.32 \pm 0.71$ & $5.74 \pm 0.43^{* *}$ & $6.49 \pm 0.14^{* * *}$ & $3.14 \pm 0.62$ \\
\hline Haematocrit (\%) & $24.95 \pm 4.95$ & $32.52 \pm 2.58$ & $37.01 \pm 0.76$ & $29.62 \pm 5.94$ \\
\hline $\operatorname{Mean}^{c}(\mathrm{fL})$ & $60.44 \pm 12.1$ & $56,22 \pm 0,86$ & $57,00 \pm 0,97$ & $87.44 \pm 11.9$ \\
\hline RDW (\%) & $15.24 \pm 3.06$ & $19.14 \pm 0.30$ & $19.53 \pm 0.13$ & $14.61 \pm 2.74$ \\
\hline MCH (Pg) & $20.4 \pm 4.23$ & $19.58 \pm 0.27$ & $19.90 \pm 0.48$ & $49.63 \pm 22.7$ \\
\hline $\mathrm{MCHC}(\mathrm{g} / \mathrm{dL})$ & $26.07 \pm 4.96$ & $34.80 \pm 0.54$ & $34.87 \pm 0.59$ & $45.68 \pm 17.0$ \\
\hline Haemoglobin $(\mathrm{g} / \mathrm{dL})$ & $9.67 \pm 0.87$ & $11.22 \pm 0.81$ & $12.90 \pm 0.27$ & $11.21 \pm 1.19$ \\
\hline RDW-SD (fL) & $31.33 \pm 4.04$ & $27.88 \pm 0.35$ & $28.44 \pm 0.41$ & $35.55 \pm 5.14$ \\
\hline $\operatorname{PLT}\left(10^{3} / \mu \mathrm{L}\right)$ & $161.55 \pm 27$ & $389.77 \pm 52 *$ & $413.44 \pm 22.9^{*}$ & $279.33 \pm 107$ \\
\hline MPV (fL) & $7.74 \pm 0.22$ & $7.26 \pm 0.10$ & $7.24 \pm 0.08$ & $8.48 \pm 0.22^{* *}$ \\
\hline PCT (\%) & $0.12 \pm 0.02$ & $0.28 \pm 0.04$ & $0.30 \pm 0.01$ & $0.23 \pm 0.09$ \\
\hline PDW (\%) & $39.31 \pm 5.08$ & $42.54 \pm 0.79$ & $41.84 \pm 1.44$ & $41.11 \pm 1.19$ \\
\hline
\end{tabular}

a103/ $\mu \mathrm{L} ; \mathrm{b} 10^{6} / \mu \mathrm{L} ;{ }^{c}$ corpuscular volume.

Values are expressed as Mean \pm SEM of 9 rats per group. Statistically significant relative to the controls, ${ }^{*} p<0.05 ;{ }^{* *} p<0.01$; $\left.{ }^{* *} p<0.001\right) ; R D W$ : distribution index of red blood cells; MCH: mean red blood cell hemoglobin content; MCHC: mean corpuscular concentration in hemoglobin; RDW-SD: standard deviation of red blood cell distribution index; MPV: mean platelet volume; PCT: procalcitonin; PDW: platelet distribution index; PLT: blood platelets.

Table 6 Effects of aqueous extract of E. speciosa on haematological parameters in female rats

\begin{tabular}{|c|c|c|c|c|}
\hline \multirow{2}{*}{$\begin{array}{l}\text { Haematological } \\
\text { parameters }\end{array}$} & \multicolumn{4}{|c|}{ Treatment groups (mg/kg) } \\
\hline & 0 & 250 & 500 & 1000 \\
\hline White Blood Cells ${ }^{a}$ & $9.80 \pm 2.11$ & $13.82 \pm 5.82$ & $8.65 \pm 3.42$ & $11.25 \pm 3.16$ \\
\hline Lymphocyte & $5.29 \pm 1.51$ & $6.72 \pm 3.10$ & $5.19 \pm 2.25$ & $5.94 \pm 2.17$ \\
\hline Mid cells total counta & $2.00 \pm 0.55$ & $1.94 \pm 0.74$ & $1.10 \pm 0.41$ & $2.19 \pm 0.63$ \\
\hline Granulocytesa & $2.49 \pm 0.47$ & $5.14 \pm 2.01$ & $2.35 \pm 0.97$ & $3.12 \pm 0.50$ \\
\hline Red blood cells ${ }^{b}$ & $5.21 \pm 0.33$ & $3.02 \pm 0.64^{*}$ & $3.23 \pm 0.80^{*}$ & $4.52 \pm 0.32$ \\
\hline Haematocrit (\%) & $37.10 \pm 2.36$ & $23.14 \pm 4.88^{*}$ & $19.25 \pm 4.55^{* *}$ & $32,52 \pm 1,17$ \\
\hline Meanc (fL) & $72.44 \pm 5.16$ & $69.88 \pm 9.22$ & $57.11 \pm 8.76$ & $74.77 \pm 5.81$ \\
\hline RDW (\%) & $20.14 \pm 0.78$ & $14.61 \pm 2.78$ & $16.47 \pm 3.20$ & $2.10 \pm 0.58$ \\
\hline MCH (Pg) & $22.75 \pm 1.35$ & $21.06 \pm 4.15$ & $18.00 \pm 3.6$ & $23.08 \pm 4.90$ \\
\hline $\mathrm{MCHC}(\mathrm{g} / \mathrm{dL})$ & $31.58 \pm 0.71$ & $27.24 \pm 5.17$ & $29.54 \pm 5.75$ & $31.11 \pm 0.91$ \\
\hline Haemoglobin (g/dL) & $11.66 \pm 0.63$ & $8.95 \pm 1.29$ & $8.24 \pm 1.08$ & $10.15 \pm 0.53$ \\
\hline RDW-SD (fL) & $35.00 \pm 1.64$ & $32.11 \pm 2.62$ & $29.44 \pm 2.16$ & $36.33 \pm 2.09$ \\
\hline $\operatorname{PLT}\left(10^{3} / \mu \mathrm{L}\right)$ & $343.11 \pm 71$ & $236.55 \pm 44$ & $228.11 \pm 35.1$ & $248.33 \pm 81.6$ \\
\hline MPV (fL) & $7.61 \pm 0.29$ & $8.22 \pm 0.22$ & $7.71 \pm 0.33$ & $7.85 \pm 0.25$ \\
\hline РCT (\%) & $0.25 \pm 0.04$ & $0.19 \pm 0.03$ & $0.17 \pm 0.02$ & $0.27 \pm 0.06$ \\
\hline PDW (\%) & $40.50 \pm 1.42$ & $44.40 \pm 1.50$ & $45.34 \pm 1.68$ & $43.77 \pm 1.03$ \\
\hline
\end{tabular}

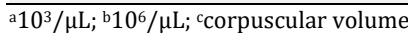

Values are expressed as Mean \pm SEM of 9 rats per group. Statistically significant relative to the controls, ${ }^{*} p<0.05$; $\left.{ }^{* *} p<0.01 ;{ }^{* * *} p<0.001\right) ; R D W$ : distribution index of red blood cells; MCH: mean red blood cell hemoglobin content; MCHC: mean corpuscular concentration in hemoglobin; RDW-SD: standard deviation of red blood cell distribution index; MPV: mean platelet volume; PCT: procalcitonin; PDW: platelet distribution index; PLT: blood platelets.

\subsection{Effect of Extract on Biochemical Parameters}

\subsubsection{Effect of E. speciosa Extract on Cholesterol Levels}

Serum cholesterol levels tended to increase as extract dose increased, but the effect was not significant. The level of testicular cholesterol was decreased in all the extract-treated groups compared with the controls. There was significant decrease $(\mathrm{p}<0.05)$ in the serum cholesterol levels in female rats treated with $250 \mathrm{mg} / \mathrm{kg}$ of extract for two weeks compared with the controls. Ovarian and uterine cholesterol concentrations increased with extract treatment especially at the $1000 \mathrm{mg} / \mathrm{kg}$ dose compared with the control group (Table 7).

Table 7 Effect of E. speciosa extract on cholesterol levels (mg/dL)

\begin{tabular}{llllll}
\hline $\begin{array}{l}\text { Treatment } \\
(\mathrm{mg} / \mathrm{kg})\end{array}$ & \multicolumn{2}{c}{ Male } & Female & & \\
\cline { 2 - 6 } & Serum & Testicular & Ovarian & Uterine & Serum \\
\hline 0 & $134.22 \pm 9$ & $69.96 \pm 0.8$ & $94.00 \pm 1.6$ & $100.06 \pm 2$ & $168.34 \pm 9.80$ \\
250 & $140.57 \pm 1$ & $68.01 \pm 0.5$ & $105.53 \pm 5$ & $128.90 \pm 21$ & $129.42 \pm 5.54^{*}$ \\
500 & $165.00 \pm 6$ & $67.22 \pm 0.2$ & $124.62 \pm 20$ & $110.64 \pm 7$ & $153.86 \pm 11.2$ \\
1000 & $143.68 \pm 8$ & $67.22 \pm 0.7$ & $115.60 \pm 3$ & $145.66 \pm 17$ & $156.01 \pm 8.94$ \\
\hline
\end{tabular}

Values are expressed as Mean \pm SEM of 9 rats per group. Statistically significant relative to the controls, ${ }^{*} p<0.05$

\subsubsection{Effect of E. speciosa Extract on Tissue Protein Levels}

Tables 8 shows that testicular, uterine, ovarian and serum total protein levels in all extract-treated male and female rats tended to increase for all doses but the differences were not significant relative to the controls. The increase in serum protein levels was more marked in females compared with the males.

https://doi.org/10.30799/jnpr.087.20060103
Table 8 Effect of E. speciosa extract on tissue total protein concentrations $(\mathrm{mg} / \mathrm{mL})$

\begin{tabular}{llllll}
\hline $\begin{array}{l}\text { Treatment } \\
(\mathrm{mg} / \mathrm{kg})\end{array}$ & \multicolumn{2}{c}{ Male } & \multicolumn{2}{c}{ Female } & \\
\cline { 2 - 6 } & Serum & Testicular & Ovarian & Uterine & Serum \\
\hline 0 & $4.23 \pm 0.17$ & $2.94 \pm 0.02$ & $3.66 \pm 0.04$ & $3.75 \pm 0.12$ & $4.57 \pm 0.10$ \\
250 & $4.22 \pm 0.17$ & $2.97 \pm 0.03$ & $3.73 \pm 0.05$ & $3.84 \pm 0.02$ & $4.22 \pm 0.12$ \\
500 & $4.11 \pm 0.17$ & $3.05 \pm 0.10$ & $3.70 \pm 0.04$ & $3.77 \pm 0.03$ & $4.85 \pm 0.11$ \\
1000 & $4.53 \pm 0.15$ & $3.14 \pm 0.07$ & $3.77 \pm 0.05$ & $3.90 \pm 0.03$ & $5.14 \pm 0.21$ \\
\hline
\end{tabular}

Values are expressed as mean \pm SEM, $n=9$

\subsubsection{Effect of E. speciosa Extract on Transaminase Activity $(u / L)$}

E. speciosa aqueous extract induced changes in the activity of ALAT and ASAT. However, at a dose of $500 \mathrm{mg} / \mathrm{kg}$, the extract caused a significant decrease $(\mathrm{p}<0.05)$ ASAT $(42.69 \pm 4.36)$ in males compared to control $(56$, $93 \pm 2.94)$. Similarly, ASAT decreased in females that received the extract at doses of 250, 500 and $1000 \mathrm{mg} / \mathrm{kg}$ and ALAT decreased in males at 250 $\mathrm{mg} / \mathrm{kg}$ compared to the corresponding controls. On the contrary, ALAT increased $(\mathrm{p}>0.05)$ in treated females and males treated at doses of 500 and $1000 \mathrm{mg} / \mathrm{kg}$ compared to the corresponding control groups (Table 9).

Table 9 Effect of E. speciosa extract on transaminase activities (U/L) in male and female albino rats

\begin{tabular}{|c|c|c|c|c|}
\hline \multirow{2}{*}{$\begin{array}{l}\text { Treatment } \\
(\mathrm{mg} / \mathrm{kg})\end{array}$} & \multicolumn{2}{|l|}{ Male } & \multicolumn{2}{|l|}{ Female } \\
\hline & $\overline{\text { ALAT }}$ & ASAT & ALAT & ASAT \\
\hline 0 & $33.32 \pm 5.86(9)$ & $56.93 \pm 2.94(8)$ & $23.55 \pm 2.86(9)$ & $61.91 \pm 5.17(6)$ \\
\hline 250 & $27.79 \pm 4.38(9)$ & $66.30 \pm 4.70(9)$ & $28.60 \pm 4.85(6)$ & $53.12 \pm 5.62(7)$ \\
\hline 500 & $35.26 \pm 5.60(9)$ & $42.69 \pm 4.36(9)$ & $35.57 \pm 6.33(9)$ & $44.09 \pm 4.64(7)$ \\
\hline 1000 & $40.25 \pm 5.68(8)$ & $62.50 \pm 3.54(9)$ & $32.55 \pm 3.30(8)$ & $50.98 \pm 5.51(7)$ \\
\hline
\end{tabular}

Values are expressed as mean \pm SEM; ( ), number of animals; ASAT: aspartate aminotransferase; ALAT: alanine aminotransferase

\subsubsection{Effects of E. speciosa Extract on Histology of the Testes and Ovaries.}

Fig. 4 shows the histological parameters in the male rats treated with the extract. The testes (A) show interstitial edema (Oe.i) with a high spermatozoa density $(250 \mathrm{mg} / \mathrm{kg}$ of bw). The animals that received the high dose extract (500-1000 mg/kg of bw); have the less developed seminal epithelium (Es).

In control and treated rats, we observed growing follicles (F) in the cortical zone of the ovary (B). In the treated rats, there is noticeable desquamation (dq) of the cells and the presence of follicular atresia (Af) (Fig. 5).
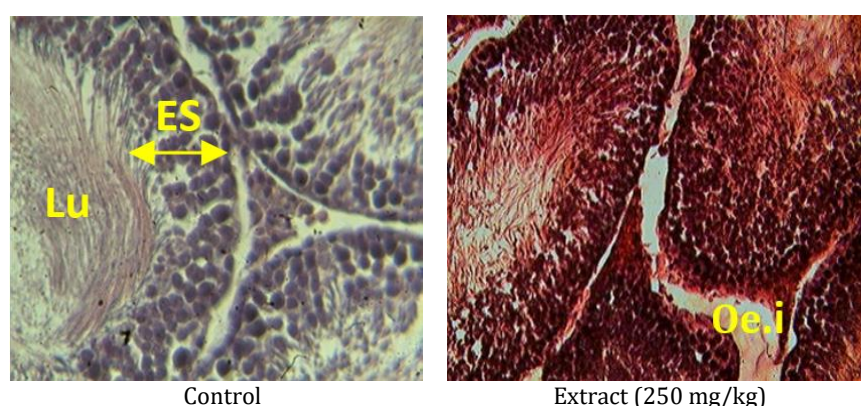

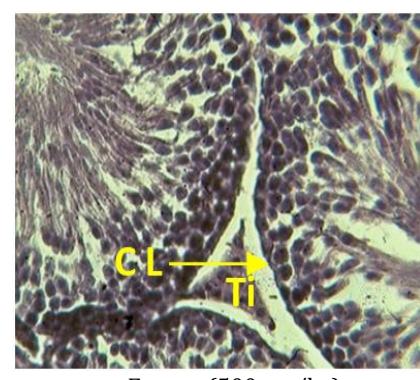

Extract $(500 \mathrm{mg} / \mathrm{kg})$

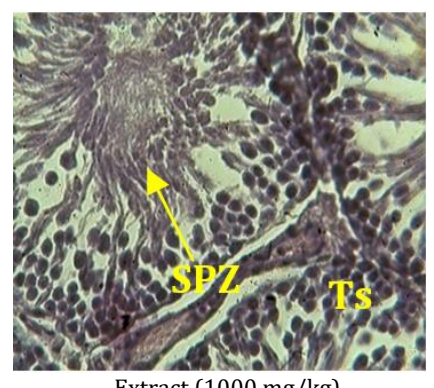

Extract $(1000 \mathrm{mg} / \mathrm{kg})$
Fig. 4 Effects of the extract on testicular histology of male rats (x 200)

Oral treatment of the rats with E. speciosa extract revealed no evident signs of toxicity in male rats. There were no significant changes in daily body weights, liver, kidney and reproductive organ weights. Significant declines in organ and body weights usually correlate to the impairment of reproduction [22]. The body weights of the male rats increased consistently during the 60 days of extract administration. In addition, no toxicity-related behavioral signs were observed. However, rats given the 500 and $1000 \mathrm{mg} / \mathrm{kg}$ of extract showed signs of diarrhea earlier in the experiment but quickly recovered during the succeeding days. Similar findings were recorded during the assessment of reproductive toxicity in 
female rats. Fetal morphology was not adversely affected, indicating that E. speciosa extract might not affect fetal development if administered before conception.

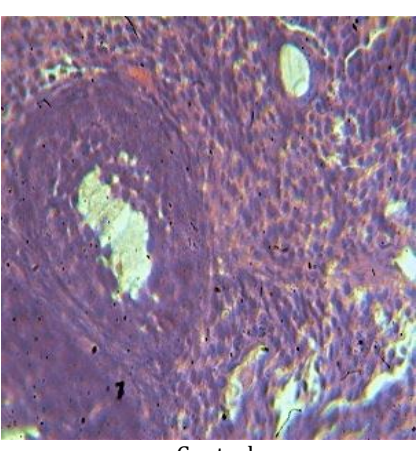

Control

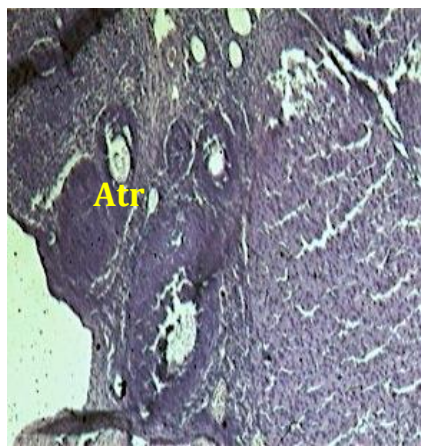

Extract $(500 \mathrm{mg} / \mathrm{kg})$

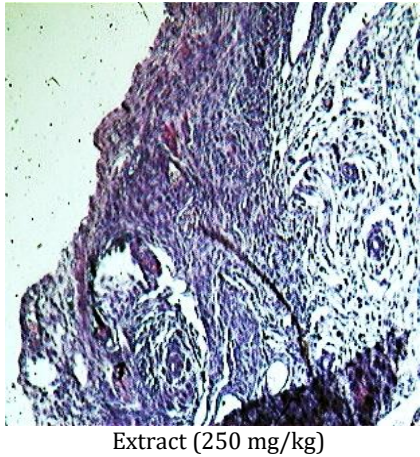

Extract $(250 \mathrm{mg} / \mathrm{kg})$

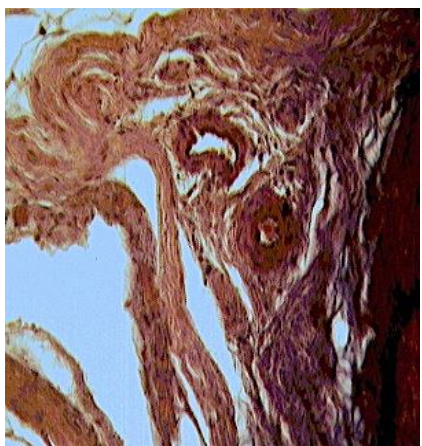

Extract $(1000 \mathrm{mg} / \mathrm{kg})$
Fig. 5 Effects of the extract on ovarian histology of treated rats (x 200)

Female reproduction is functionally controlled by normal estrogen levels which usually peak during the estrous phase of the reproductive cycle. In the female rats, both ovarian and uterine cholesterol and protein levels increased with administration of E. speciosa extract, while serum levels decreased especially at the $250 \mathrm{mg} / \mathrm{kg}$ dose. The high affinity of the uterus and ovary for cholesterol and proteins during the reproductive cycle would be responsible for the observed drop in serum concentrations. This suggests that E. speciosa extract may have estrogenic effects in the ovary. The extract had no significant effects on male testicular and serum cholesterol and total protein levels except for the observed serum cholesterol spike observed for the $500 \mathrm{mg} / \mathrm{kg}$ of bw dose. The significant drop in ovarian weights at the highest dose of extract indicates toxic effects that could be due to extract-induced degeneration of the follicular walls. Ovarian histology shows follicular atresia.

Following treatment of female rats for 14 days, the mean number for corpora lutea increased and the number of resorptions decreased. In addition, copulation and fertility rates increased. These changes suggest that $E$. speciosa extract may have beneficial effects on female reproductive function.

At the doses employed, there were no adverse effects on the mean weights of liver, kidney, heart, lungs and spleen which were consistent with previous studies. Also, there were no treatment- related abnormalities in the body weights of the female rats throughout the period of treatment. Body weight is well known to play an important role in the regulation of gonadotrophin secretion and plays a crucial role for regular cyclic function $[23,24]$.

The significant decrease in the testicular weights of male rats treated with the extract for 60 days is not readily explainable. The results of testicular histology corroborate those of their relative weight. In the extract-treated rats, interstitial edema and a small thickness of seminal epithelium were observed. Extract treatment resulted in increased sperm count and motility at the dose of $250 \mathrm{mg} / \mathrm{kg}$. This effect may occur through increased activity of lactate dehydrogenase activity which has been reported to be related to sperm counts and motility [25] as a result of its involvement in the energy-supply metabolic processes. The extract may therefore contain phytochemicals which may improve spermatogenesis at the level of the germinal epithelium. Increases in sperm motility caused by chemical agents had earlier been reported to be due to their ability to permeate the blood-testis diffusion barrier [26]. At higher doses, there was a drop in sperm motility which could be accounted for by the observed dose-dependent increase in the number of deformed spermatozoa. There were no significant decreases in testicular cholesterol levels (precursor of testosterone) to support the possible implication of reduced androgenic effects by the extract. Testosterone is required for the growth, development and maintenance of male reproductive organs [27] and in association with follicle stimulating hormone, acts on the seminiferous tubules to initiate and maintain spermatogenesis [28]. However, these potential adverse effects of extract at high doses did not have negative effects on male sexual performance and fertility rates.

In the present study, there were significant increases in erythrocytes values in the male rats given the extract of Eremomastax for 60 days, suggesting that the extract would confer good respiratory capability to the animals during sexual function. The corresponding significant increase in the hematocrit of extract-treated animals confirms the widely reputed use of the extract in the treatment of cases of anaemia [6]. The mean values of $\mathrm{RBC}, \mathrm{WBC}$ and hematocrit in rats given the extract were within the normal physiological ranges of $5.79-7.14 \times 10^{6} \mu \mathrm{L}, 5.5-12.1 \times 10^{3} \mu \mathrm{L}$ and $32-40 \%$, respectively, reported by CRL (1982) [26] for young and adult male rats.

On the contrary, the extract may have negative effects on hematological status in females in which erythrocyte and hematocrit values dropped significantly. The mean values of RBC, WBC and hematocrit of pregnant extract-treated rats were not within the normal physiological ranges of 6.2 $-7.64 \times 10^{6} \mu \mathrm{L}, 4.19-9.73 \times 10^{3} \mu \mathrm{L}$ and $34-42 \%$, respectively, reported by CRL (1982) [29] for young and adult female rats. The results suggest that the animals could have suffered from leukocytosis, which may result from intoxications including those produced by metabolic disturbances [30].

Hepato-renal toxicity was studied by measurement of some biochemical parameters. ALAT is a cytosolic enzyme secreted in the liver cells where it is released into the bloodstream when liver cell necrosis occurs [31]. It is a specific enzyme in the liver, making it an important and very sensitive indicator of hepatotoxicity [32]. ASAT is also an indicator of hepatocyte destruction even if, in addition to the liver, it is also found in the heart, skeletal muscle, lungs and kidneys [31]. ALAT and ASAT levels rise rapidly when the liver is damaged for various reasons including hepatic cell necrosis, hepatitis, cirrhosis and liver toxicity of certain drugs [33]. In the present study, ALAT levels tended to increase in female and male rats (at doses above $250 \mathrm{mg} / \mathrm{kg}$ ), and ASAT levels tended to decrease in the females but the differences were not statistically significant compared with the controls. These results suggest that the extract may not have hepatoprotective effects at high doses in spite of the presence of flavonoids [17], molecules with known hepatoprotective activity [34]. Previous studies on the acute and subacute toxicity of E. speciosa aqueous extract led to the recommendation of the $250 \mathrm{mg} / \mathrm{kg}$ dose for therapeutic use since higher doses $(800-1600 \mathrm{mg} / \mathrm{kg}$ ) caused histopathological signs in the lungs (diffuse alveolar damage), kidneys (tubular cell necrosis, reduced glomerular space, scattered inflammation) and liver (vascular congestion, biliary stasis) [35]. The results of the present study are in line with the earlier recommendation.

\section{Conclusion}

Administration of E. speciosa aqueous extract in male rats for 60 days caused a decrease in relative testes weights, and increased epididymal weights. These effects were accompanied by a significant increase in the density and motility of spermatozoa. In the female rats, high doses of extract resulted in decreased ovarian weights and reduced counts of some haematological parameters, but these effects had no observable negative influence on the reproductive performance of the rats. The extract of $E$. speciosa can be safely used by reproducing couples (prior to and in the early stages of pregnancy) at the dose of $250 \mathrm{mg} / \mathrm{kg}$ for the management of various disease conditions without the risk of reproductive toxicity.

\section{Acknowledgements}

This work was carried out with the contributing support of the authors. Authors B. Nchegang and P.V. Tan designed the study and wrote the protocol, did the literature search, analysis of histological sections, and statistical analysis. Authors B. Nchegang, Z.E. Nkwengoua and P.A. Amang did the phytochemical study of the plant. Authors B. Nchegang and C. Mezui managed the biochemical analysis. Author B. Nchegang wrote the first draft, and author P.V. Tan supervised the study.

\section{References}

[1] L. Goldfrank, H. Lewin, N. Flomenbaum, M.A. Howland, The Pernicious panaced Herbal Medicine, Hosp. Phys. 10 (1982) 64-86.

[2] S.M.K. Rates, Plants as source of drugs, J. Toxicon. 39 (2001) 603-613.

[3] A. De Pasquale, Pharmacognosy: The oldest modern science, J. Ethnopharmacol. 11 (1984) 1-16.

[4] WHO, Reproductive toxicology guidelines: Comparation and application, World Health Organization, Geneva, 1993. 
[5] H. Heine, Flora of Gabon: Acanthaceae, National Museum of Natural History, Paris 3 (1966) 29-32.

[6] J.E. Okokon, B.S. Antia, A.E. Udoh, M.M. Akpan, Antianaemic and antimicrobial activity of Eremomastax speciosa, J. Pharmacol. Toxicol. 2 (2007) 196-199.

[7] J.E. Oben, S.E. Assi, G.A. Agbor, D.F Musoro, Effect of Eremomastax speciosa on experimental diarrhea, African J. Trad. Compl. Altern. Med. 3(1) (2006) 95100.

[8] S.D. Dibong, M.E. Mpondo, A. Ngoye, R.J. Priso, Modalities of exploitation of medicinal plants in Douala's region, Am. J. Fd. Nutr. 1(2) (2011) 67-73.

[9] E.N. Ndenecho, Herbalism and resources for the development of ethopharmacology in Mount Cameroon region, Afr. J. Pharm. Pharmacol. 3(3) (2009) 078- 086

[10] O.E. Mboso, E.U. Eyong, M.O. Odey, E. Osakwe, Comparative phytochemical screening of Ereromastax speciosa and Ereromastax polysperma, J. Nat. Prod. Plant Res. 3(2) (2013) 37-41.

[11] P.B. Telefo, M.C. Lemfack, B. Bayala, Ethnopharmacological survey of medicinal plants used in women infertility treatment in Fossong-Wentcheng and Foto villages, Western Region of Cameroon, J. Phytotherapy. 10(1) (2012) 25-34.

[12] J.O. Erhabor, M. Idu, F.O. Udo, Ethnomedicinal survey of medicinal plants used in the treatment of male infertilty among the IFA- Nkari People of Ini Local Government area of Akwa-Ibom State, Nigeria, Res. J. Recent Sci. 2 (2013) 511.

[13] D.A. Focho, W.T. Ndam, B.A. Fonge, Medicinal plants of Aguambu-Bamumbu in the Lebialem highlands, Southwest Province of Cameroon, Afr. J. Pharm. Pharmacol. 3(1) (2009) 001-013.

[14] J.E. Adjanahoun, N. Aboubakar, K. Dramane, M.E. Ebot, J.A. Ekpere, et al., OUA/STRC traditional medicine and pharmacopoeia: contribution to ethnobotanical and floristic studies in Cameroon, CNPMS, Porto Novo, Benin., 1996.

[15] N.R. Mshana, D.K. Abbiw, I. Addae-Mensah, E. Adjanohoun, M.R.A. Ahyi, et al., Traditional medicine and pharmacopoeia: contribution to the revision of etnobotanical and floristic studies in Ghana, Scientific, Technical and Research Commission of the Organization of African Unity, Ghana, 2000, pp.290-293.

[16] P.V. Tan, N.G. Nditafon, M.P. Yewah, T. Dimo, F.J. Ayafor, Eremomastax speciosa: Effect of leaf aqueous extract on ulcer formation and gastric secretion in rats, J. Ethnopharmacol. 54 (1996) 139-142.

[17] A.P. Amang, P.V.Tan, Z.E . Nkwengoua, B. Nyasse, Antisecretory action of the extract of the aerial parts of Eremomastax speciosa (Acanthaceae) occurs through antihistaminic and anticholinergic pathways, Adv. Pharmacol. Sci. 2014 (2014) 323470:1-10.

[18] F. Wroblewski, P. Ruegsegger, J.S. Ladue, Serum lactic dehydrogenase activity in acute transmural myocardial infarction, Sci. 123(3208) (1956) 1122-1123.

[19] A.G. Gornal, G.S. Bardwil, M.M. David, Determination of serum proteins by means of the Biuret reactions, J. Bioch. 177 (1949) 751-766.
[20] T.J. Youmbissi, S. Djoumessi, C. Nouedoui, P. Ndobo, J. Meli, Lipid profile of a group of hypertensive black African Cameroonians, Med. Afr. Noir. 48(7) (2001) 305-314.

[21] A.O. Akpantah, A.A. Oremosu, M.O. Ajala, C.C. Noronha, A.O. Okanlawon, The effect of crude extract of Garcinia kola seed on the histology and hormonal milieu of male Sprague-Dawley rats' reproductive, organs, Nig. J. Hlth. Biomed. Sci. 2(1) (2003) 40-46.

[22] G.C. Jain, H. Pareek, S. Sharma, M. Bhardwaj, B.S. Khajja, Reproductive toxicity of vanadyl sulphate in male rats, J. Hlth. Sci. (2007) 137-141.

[23] U.A. Knuth, M.G. Hull, H.S. Jacobs, Amenorrhea and loss of weight, Br. J. Obst. Gynecol. 84 (1977) 801-807.

[24] N.B. Schwartz, A model for the regulation of ovulation in the rat, Rec. Progr. Horm. Res. 25 (1969) 1-55.

[25] N.M. Gerez de Burgos, C. Burgos, C.E. Coronel, A. Bertarelli de Camusso, T. Pigini, A. Blanco, Correlation of lactate dehydrogenase isoenzyme C4 activity with the count and motility of human spermatozoa, J. Reprod. Fert. 55 (1979) 107-111.

[26] A.A. Dua, S.R. Vaidya, Sperm motility and morphology as changing parameters linked to sperm count variations, J. Postgrad. Med. 42 (1996) 93-96.

[27] A.D. Mooradan, J.E. Morley, S.G. Koreman, Biological actions of androgens, Endo. Rev. 8 (1987) 1-28.

[28] A.C. Christensen, Leydid cell: In handbook of physiology, P.O. Greep, E.B. Astwoods (Eds.), American Physiological Society, Washington D.C., 1975.

[29] CRL, Baseline haematology and clinical chemistry values for Charles River Wistar rats CRL: (WI)BR as a function of sex and age, CRL Tech. Bull. 1(2) (1982) 1-4.

[30] E.H. Coles, Veterinary clinical pathology, $4^{\text {th }}$ Ed., W.B. Saunders Company. Philadelphia, USA, 1986, pp.56-58.

[31] D.R. Dufour, J.A. Lott, F.S. Nolte, D.R. Gretch, R.S. Koff, L.B. Seeff, Diagnosis and monitoring of hepatic injury II. Recommendation for use of laboratory tests in screening, diagnosis and monitoring, Clin. Chem. 46 (2000) 2050-2068.

[32] M. Al-Habori, A. Al-Aghbari, M. Al-Mamary, M. Baker, Toxicological evaluation of Catha edulis leaves: a long-term feeding experiment in animals, J. Ethnopharmacol. 83 (2002) 209-217.

[33] D.S. Pratt, M.M. Kaplan, Evaluation of abnormal liver-enzyme results in asymptomatic patients, N. Engl. J. Med. 342 (2000) 1266-1271.

[34] R.K. Narayana, S.M Reddy, M.R. Chaluvadi, D.R. Krishna, Bioflavonoids classification, pharmacological, biochemical effects and therapeutic potential, Ind. J. Pharmacol. 33 (2001) 2-16.

[35] G.T. Siwe, G.E. Enow-Orock, A.P. Amang, C. Mezui, A.B. Dongmo, P.V.Tan, Acute and sub-acute toxicological assessment of the leaf aqueous extract of Eremomastax speciosa (Acanthaceae) in wistar rats, J. Adv. Med. Pharmaceut. Sci. 4(1) (2015) 1-13 